\title{
New insights into the biology and ecology of Acanthocheilonema reconditum (spirurida: onchocercidae)
}

\author{
E Napoli', G Gaglio', L Falsone', S Giannetto', F Dantas-Torres ${ }^{2,3}$, D Otranto², E Brianti ${ }^{1 *}$ \\ From The 1st Conference on Neglected Vectors and Vector-Borne Diseases (EurNegVec): with Management \\ Committee and Working Group Meetings of the COST Action TD1303 \\ Cluj-Napoca, Romania. 8-11 April 2014
}

Among filarioids infesting dogs, Acanthocheilonema reconditum has a global distribution and epidemiological data indicate that it is the most prevalent or even the sole filarioid species-infecting dogs in some regions of the Mediterranean basin. For instance, in southern regions of Italy the prevalence is as high as $13.3 \%$, and an annual incidence of $5.9 \%$ was estimated in naturally exposed dogs. In spite of its wide distribution and its suspected zoonotic potential, scant information is available on the biology of this filarioid. Nonetheless, recent studies have enhanced current scientific knowledge on the biology and ecology of this nematode in naturally infected dogs. Recent data indicate the absence of any defined periodicity of blood circulating microfilariae with peaks recorded either diurnal or nocturnal. With regard to the life cycle, fleas were confirmed to be vectors of $A$. reconditum, whereas the role of ixodid ticks (i.e., Rhipicephalus sanguineus sensu lato) as vectors of this filarioid species has been definitively rejected. The full development of microfilariae to infective forms occurs in the experimental infected cat flea Ctenocephalides felis felis in about 15 days. In addition, localization and size of developing larvae inside infected flea suggest that this arthropod might act as an intermediate host throughout the ingestion of infected fleas rather than the inoculation during the blood meal on dogs. If confirmed, this route of A. reconditum transmission is unique, differing from that of other filarioids affecting dogs such as Dirofilaria immitis and Dirofilaria repens, which are actively transmitted through the bites of mosquito vectors.

* Correspondence: ebrianti@unime.it

'Dipartimento di Scienze Veterinarie, University of Messina, Messina, Italy

Full list of author information is available at the end of the article
Authors' details

'Dipartimento di Scienze Veterinarie, University of Messina, Messina, Italy. ${ }^{2}$ Dipartimento di Medicina Veterinaria, University of Bari, Bari, Italy.

${ }^{3}$ Department of Immunology, Aggeu Magalähes Research Institute, Oswaldo Cruz Foundation, Recife, Brazil.

Published: 1 April 2014

doi:10.1186/1756-3305-7-S1-029

Cite this article as: Napoli et al: New insights into the biology and ecology of Acanthocheilonema reconditum (spirurida: onchocercidae). Parasites \& Vectors 2014 7(Suppl 1):O29.

Submit your next manuscript to BioMed Central and take full advantage of:

- Convenient online submission

- Thorough peer review

- No space constraints or color figure charges

- Immediate publication on acceptance

- Inclusion in PubMed, CAS, Scopus and Google Scholar

- Research which is freely available for redistribution 